\title{
The distribution and expression profiles of human Aspartyl/Asparaginyl beta-hydroxylase in tumor cell lines and human tissues
}

\author{
HUI YANG ${ }^{1}$, KAI SONG ${ }^{1}$, TIAN XUE ${ }^{2}$, XIAO-PING XUE ${ }^{1}$, TING HUYAN $^{1}$, WEI WANG ${ }^{1}$ and HUA WANG ${ }^{1}$ \\ ${ }^{1}$ Faculty of Life Sciences, Northwestern Polytechnical University, Xi'an 710072; \\ ${ }^{2}$ Department of Life Sciences, Northwestern University, Xi'an 710069, P.R. China
}

Received April 30, 2010; Accepted June 16, 2010

DOI: $10.3892 /$ or_00000980

\begin{abstract}
Human aspartyl beta-hydroxylase (HAAH) is a highly conserved enzyme that hydroxylates epidermal growth factor-like domains in transformation-associated proteins. Previous studies showed that the HAAH gene was overexpressed in many human malignancies. The present study investigates the distribution and expression profiles of HAAH in a variety of tumor cell lines and human tissues. One hundred and four cases of carcinomas were retrieved from the pathology archives of Department of Pathology, First Affiliated Hospital of Medical College of Xi'an Jiaotong University. Paraffinembedded tissue specimens were immunostained with the HAAH monoclonal antibodies (MAb) generated to naked plasmid DNA containing $\mathrm{N}$-terminal domain of the encoding HAAH gene and recombinant HAAH. Immunoreactivity was detected in $90.4 \%$ (94 positive cases) of carcinomas, including $88.5 \%$ of strong positive cases. In addition, HAAH mRNA levels were measured in seven tumor cell lines and in normal tissue. The results demonstrated that HAAH was highly expressed in the tumor cell lines in contrast to its low level of expression in normal tissue. The protein expression level of HAAH in the tumor cell lines by Western bolt analysis was comparable to the mRNA expression level. HAAH distribution in seven tumor cell lines was analyzed by immunofluorescence cell staining. The antigen was primarily localized in cytoplasm and plasmalemma. HAAH mAb exhibited high level binding to the four tumor cell lines (breast carcinoma MCF-7, hepatic carcinoma SMMC-7721, cervix cancer HeLa and ovary cancer SKOV) and lower degrees of binding were observed with the other three (renal adenocarcinoma $\mathrm{ACHN}$, bladder cancer BIU-87 and laryngeal cancer Hep-2). In contrast, normal mouse
\end{abstract}

Correspondence to: Dr Xiao-ping Xue, Faculty of Life Sciences, Northwestern Polytechnical University, 127 Youyi Road, Xi'an 710072, P.R. China

E-mail: xuexp99@gmail.com

Key words: aspartyl beta-hydroxylase, carcinomas, tumor-marker embryonic osteoblasts MC3T3 exhibited no staining. In conclusion, HAAH is overexpressed frequently a variety of carcinomas, indicating that overexpression of the enzyme correlates with the development and progression of carcinomas and it could serve as a prognostic biomarker to predict the clinical course of some carcinomas.

\section{Introduction}

Cancer is one of the most serious diseases in the world today, also occurring with high frequency in China. Early detection, diagnosis and treatment are important for improving the treatment of malignant tumors and prolonging the lives of patients. Although many tumors are detectable by ultrasonography, helical computed tomography, or magnetic resonance imaging, these approaches seldom reveal tumors that are $<1 \mathrm{~cm}$ in diameter $(1,2)$. Therefore, these methods are limited for detecting tumors at an early stage. Some molecular factors such as expression of genes, tumor proliferative indices, nuclear DNA ploidy, growth factors, and hormone receptors have been used to predict clinical outcome in patients with tumors $(3,4)$. Specific and sensitive biomarkers for tumors would be used to detect preclinical disease, and to target therapy if the associated antigens are expressed on the cell surface.

The human aspartyl beta-hydroxylase (HAAH) is a protein belonging to the $\alpha$-ketoglutarate-dependent dioxygenase family of prolyl and lysyl hydroxylases, which play a key role in collagen biosynthesis. This molecule hydroxylates aspartic acid or asparagine residues in certain EGF-like domains of several proteins in the presence of ferrous iron (5-10). These EGF-like domains contain conserved motifs that form repetitive sequences in diverse proteins, such as clotting factors, extracellular matrix proteins, low-density lipoprotein receptor, Notch homologues or Notch ligand homologues, which have demonstrated roles in cell motility or adhesion $(5,6,8,11)$. Aspartyl beta-hydroxylase studies have shown that the gene is upregulated in a broad range of human malignancies such as breast, hepatic, biliary, colon, pulmonary, pancreatic and neural origin (12-16). Overexpression of the protein is closely related with tumor cell formation, proliferation, invasion, metastasis, differentiation, oncogenesis and cellular functions that propagate the malignant phenotype. 
It is considered as a potential broad-spectrum tumor marker. However, the roles of the enzyme in these functions are still not well understood.

In this study, the expression and distribution of HAAH was examined in different tumor cell lines and tissues of Chinese patients using reverse transcriptase-polymerase chain reaction, Western blot and immunofluorescence cell staining. We also determined whether the enzyme could serve as a prognostic biomarker to predict behavior of the clinical course of some carcinomas.

\section{Materials and methods}

Cell lines and human tissues. The tumor cell lines of human renal adenocarcinoma ACHN, bladder cancer BIU-87, breast carcinoma MCF-7, hepatic carcinoma SMMC-7721, laryngeal cancer Hep-2, cervix cancer HeLa, ovary cancer SKOV and mouse embryonic osteoblasts MC3T3 were purchased from Wuhan Cell Institute of Chinese Academy of Sciences. They were maintained in MEM or RPMI-1640 cell culture mediums (Gibco BRL, Gaithersburg, MD, USA) supplemented with $10 \%$ fetal calf serum heat-inactivated at $56^{\circ} \mathrm{C}, 10 \mathrm{mM}$ nonessential amino acids, 1,000 IU/ml of penicillin, and $100 \mathrm{mg} / \mathrm{ml}$ of streptomycin in a humidified $5 \% \mathrm{CO}_{2}$ atmosphere at $37^{\circ} \mathrm{C}$.

Samples of normal human tissues and tumor tissues paired with adjacent uninvolved tissues of cancer patients were obtained by surgical excision. One part of the tissues was snapfrozen in liquid nitrogen immediately and stored at $-80^{\circ} \mathrm{C}$. The other part was fixed in $10 \%$ buffered formalin and embedded in paraffin. This study was approved by the institutional review board at the First Affiliated Hospital of Medical College of Xi'an Jiaotong University.

Extraction of mRNA and preparation of cDNA. Total RNA was respectively extracted from $\sim 4 \times 10^{6}$ cells of the tumor and normal cell lines and then was used to establish and validate the RT-PCR assays. Serial dilutions of cDNA from target PCR products served as positive controls and for quantification in each PCR run. Total RNA was extracted using TRIzol Reagent (Invitrogen Life Technologies, Carlsbad, CA) in accordance with the manufacturer's standard protocol. cDNA was reverse-transcribed from $2 \mu \mathrm{g}$ of the extracted RNA in a $20-\mu 1$ reaction system containing the following: $2 \mu 1$ of $5 \mathrm{X}$ reaction buffer, $1 \mu 1$ of M-MLV reverse transcriptase (Promega), $1 \mu 1$ of RNAsin (Toyobo), $2 \mu 1$ of $0.1 \mathrm{M}$ DTT, $1 \mu 1$ of oligo-dT primers $(50 \mu \mathrm{g} / \mathrm{ml})$ (Promega), $6 \mu \mathrm{l}$ of dNTP mix (10 mM) (Promega) and DEPC-treated water. The samples were heated to $70^{\circ} \mathrm{C}$ for $5 \mathrm{~min}$, followed by incubation at $42^{\circ} \mathrm{C}$ for $1 \mathrm{~h}$. Reactions were terminated by heating at $95^{\circ} \mathrm{C}$ for $5 \mathrm{~min}$. 3 -actin RNA levels measured in parallel reactions were used to calculate relative abundance of each mRNA transcript.

$R T-P C R$. RT-PCR was performed in a $25-\mu 1$ reaction mixture containing $2 \mu \mathrm{l}$ of cDNA template, $20 \mu \mathrm{M}$ of each primer, and $1 \mathrm{U}$ of Taq DNA Polymerase (AmpliTaq Gold; Roche Molecular Systems, Pleasanton, CA, USA), as follows: after one cycle at $95^{\circ} \mathrm{C}$ for $5 \mathrm{~min}, 30$ cycles at $95^{\circ} \mathrm{C}$ for $30 \mathrm{sec}$, $56^{\circ} \mathrm{C}$ for $30 \mathrm{sec}$, and $72^{\circ} \mathrm{C}$ for $30 \mathrm{sec}$, followed by $72^{\circ} \mathrm{C}$ for $10 \mathrm{~min}$. The nucleotide sequences for the primer pairs are
Table I. Specific primers for RT-PCR studies.

\begin{tabular}{llc}
\hline Primer & \multicolumn{1}{c}{ Sequence $\left(5^{\prime} \rightarrow 3^{\prime}\right)$} & $\begin{array}{c}\text { Amplicon } \\
\text { size }(\mathrm{bp})\end{array}$ \\
\hline HAAH-F & GTTACCACGTGGAAGAGAC & 160 \\
HAAH-R & GCTTGTTCCTCATAGACTTG & \\
B-actin-F & ATTGAACACGGTATTGTCACC & 385 \\
B-actin-R & GTCAGGATCTTCATGAGGTAGTC & \\
\hline
\end{tabular}

shown in Table I. Experiments were performed in triplicate and repeated twice. The PCR products were separated by electrophoresis on $1 \%$ agarose gels.

Immunofluorescence cell staining. Cultured cells were grown on sterile glass slides overnight at $37^{\circ} \mathrm{C}$. They were washed briefly with PBS and fixed by the following procedures: $15 \mathrm{~min}$ in 4\% paraformaldehyde in PBS, and washed 3 times with PBS. The fixed cells were then permeabilized for $30 \mathrm{~min}$ with $2 \%$ Triton $\mathrm{X}-100$, blocked at $37^{\circ} \mathrm{C}$ for $1 \mathrm{~h}$ with $1 \% \mathrm{BSA}$, and incubated for $2 \mathrm{~h}$ with anti-HAAH monoclonal antibody (generated by immunizing mice with naked plasmid DNA containing N-terminal domain of encoding HAAH gene and recombinant HAAH polypeptide) (17) in $0.2 \mathrm{ml}$ of PBS-BSA. After washing thrice, fluorescein isothiocyanate-conjugated goat anti-mouse IgG (1:200) (Wuhan BoShiDe Biotechnology, Wuhan, China) and Hoechst 33258 were added to the cells and incubated at $37^{\circ} \mathrm{C}$ for $1 \mathrm{~h}$ in dark. The cells were washed thrice again, and mounted with 50\% glycerol/PBS mountant. The slides were then viewed under a fluorescent microscopy.

Western blotting. Western blotting was performed as previously described (18). In brief, $1 \times 10^{7}$ cells were washed once with ice-cold PBS and then detached by the addition of trypsinEDTA solution. The cell suspensions were transferred into $1.5 \mathrm{ml}$ tubes. After centrifugation $(10 \mathrm{~min}$ at $1,500 \mathrm{x} \mathrm{g})$, the supernatant was discarded, and the pellets were resuspended in $1 \mathrm{ml}$ of sample loading buffer $(62.5 \mathrm{mM}$ Tris- $\mathrm{HCl}, \mathrm{pH} 6.8$, $10 \%$ glycerol, $2 \%$ SDS, $5 \%$ ß-mercaptoethanol, $0.1 \%$ bromophenol blue). Samples were electrophoresed on a $12.5 \%$ SDS-polyacrylamide gel (19) and then transferred onto a nitrocellulose membrane (Millipore Co., Billerica, MA, USA). The membranes were blocked and then incubated for $2 \mathrm{~h}$ with mouse anti-HAAH antibody or rabbit anti-GAPDH (glyceraldehyde-3-phosphate dehydrogenase) antibody (Guangzhou LanBo Biotechnology, Guangzhou, China). After washing, the membrane was incubated with horseradish peroxidase-conjugated goat anti-mouse $\operatorname{IgG}(1: 2,000)$ or goat anti-rabbit $\operatorname{IgG}(1: 2,000)$ (Wuhan BoShiDe Biotechnology). Development was performed with $\mathrm{H}_{2} \mathrm{O}_{2}$ and dianilinobenzene as the substrates. The signal was detected under a fluorescent microscopy.

Immunohistochemistry. MAb HAAH was preliminarily applied to evaluate and localize the expression of HAAH in 19 kinds of tumor tissues of 104 specimens and non-tumor tissues by immunohistochemical stain. Paraformaldehyde fixed (2\%), paraffin-embedded tumor tissues, together with adjacent 


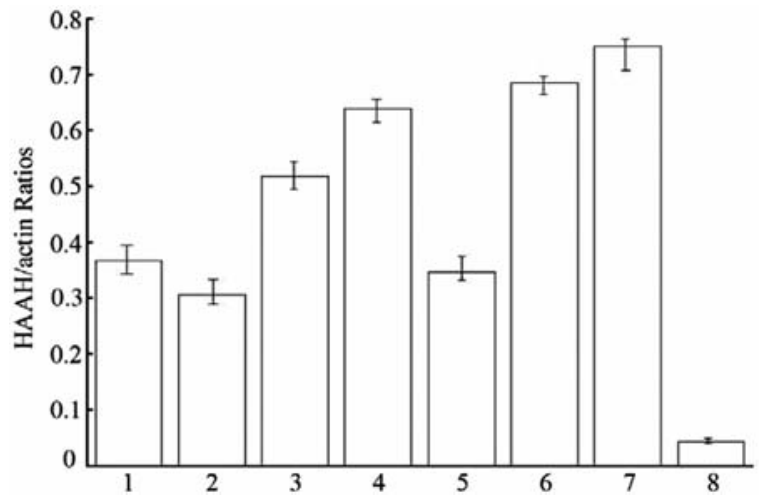

Figure 1. Mean \pm SEM levels of HAAH mRNA in tumor cell lines and normal tissue are depicted. In addition, the mean levels of $\beta$-actin measured in the paired samples are illustrated. 1, ACHN; 2, BIU-87; 3, MCF-7; 4, SMMC-7721; 5, Hep-2; 6, HeLa; 7, SKOV; 8, Normal tissue.

uninvolved tissues were studied. In addition, some normal human tissues were also fixed and paraffin embedded. The sections $(8-\mathrm{mm})$ were deparaffinized in xylenes, rehydrated in graded alcohol solution, and equilibrated in PBS. After an overnight incubation at $4^{\circ} \mathrm{C}$ with $\mathrm{HAAH} \mathrm{mAb}(5$ or $10 \mu \mathrm{g} / \mathrm{ml})$, the sections were immunostained by the avidin-biotin horseradish peroxidase complex method, according to the manufacturer's protocol (Vector Laboratories, Inc., Burlingame, CA), and with 3-3'-diaminobenzidine $(0.5 \mathrm{mg} / \mathrm{ml}$ in $0.03 \%$ hydrogen peroxide) as the chromagen. The sections were lightly counterstained with hematoxylin, dehydrated, cleared, and mounted with cover glass. We regarded cells as immunoreactive for HAAH when the signal was clearly observed in the cell surface membranes and/or cytoplasm. Equivocal stains were considered negative.

The intensity of HAAH staining was scored as negative $(0)$, weak $(+1)$, positive $(+2)$, or strong positive $(+3)$. The scores corresponding to overall distribution of HAAH immunoreactivity were averaged across the different tumor plugs per case. All sections were scored independently by 2 pathologists (K. Song and T. Huyan) in a blinded fashion, that is, without knowledge of the clinicopathologic features or clinical course.

Statistical analysis. All statistical analyses were performed using the SPSS software (SPSS, Chicago, IL). The differences between the HAAH mRNA or protein overpression in tumor and non-tumor cells or tissues were statistically analyzed using paired t-test or unpaired Student's t-test for single comparisons, and one-way analysis of variance (ANOVA) for multiple comparisons. P-values were set at the 0.05 level of significance.

\section{Results}

RT-PCR results of overexpression of Aspartyl beta-hydroxylase in tumor cell lines. HAAH mRNA levels were measured by RT-PCR, with values normalized to B-actin quantified in the same samples. The relative HAAH and $\beta$-actin gene expression levels in tumor cell lines and normal tissues were depicted in Fig. 1. The results demonstrated higher levels of HAAH mRNA in all $7(100 \%)$ tumor cell lines relative to the normal tissue (Fig. 2). There are statistically significant differences between them $(\mathrm{P}<0.01)$. In contrast, the mean levels of $\beta$-actin were similar in the tumor cell lines and the normal tissue. The mean level of HAAH mRNA in normal tissue was respectively 16.7-fold (SKOV), 15.3-fold (HeLa), 14.3-fold (SMMC-7721), 11.5-fold (MCF-7), 8.2-fold (ACHN), 7.74fold (Hep-2) and 6.8-fold (BIU-87) lower compared with those in the tumor cell lines. These RT-PCR results correlated well with the findings by Western blot analysis using the HAAH monoclonal antibody.

Immunofluorescence cell stain analysis of localization of $H A A H$ in tumorous cells. The HAAH mAb was initially

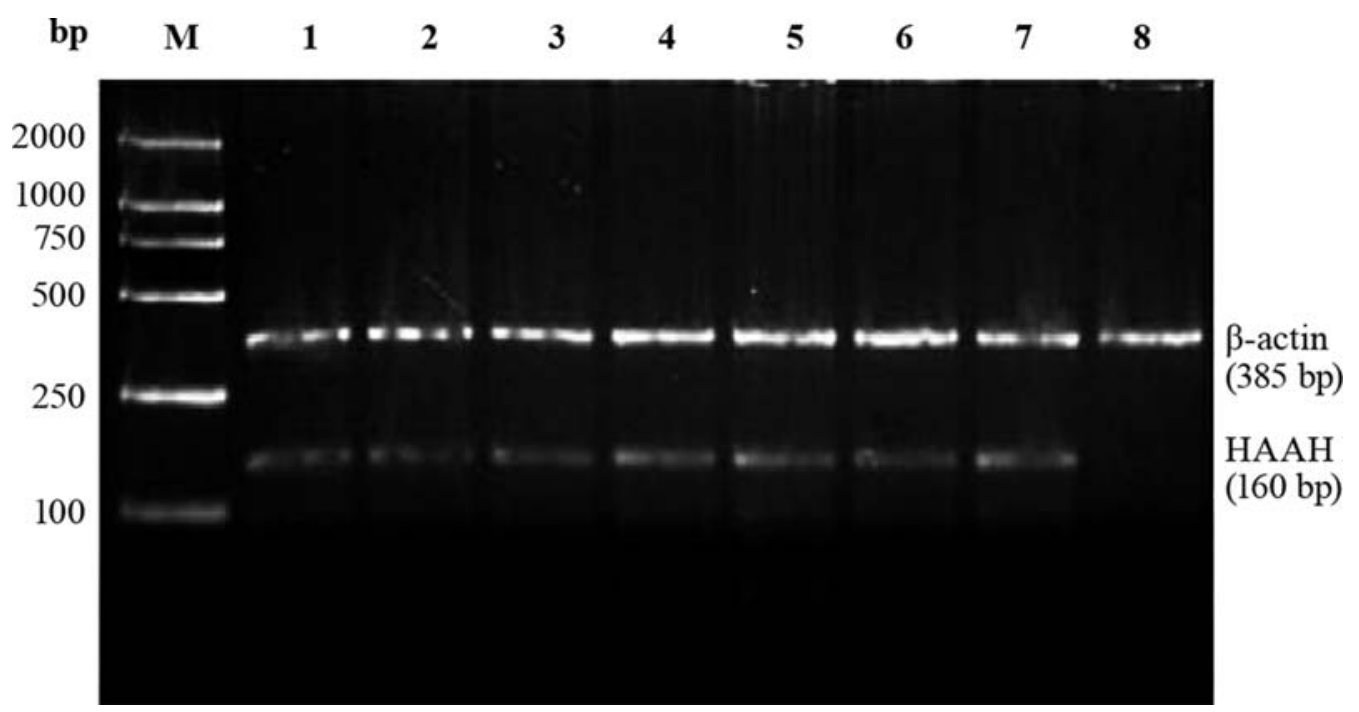

Figure 2. RT-PCR amplification of mRNA showed aspartyl beta-hydroxylase mRNA expression in seven tumor cell lines, normal tissue and mouse embryonic osteoblasts MC3T3 cell line. Marker, DNA ladder marker DL2000; 1, ACHN; 2, BIU-87; 3, MCF-7; 4, SMMC-7721; 5, Hep-2; 6, HeLa; 7, SKOV; 8, Normal tissue. 


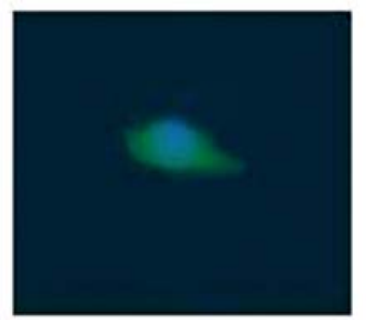

A

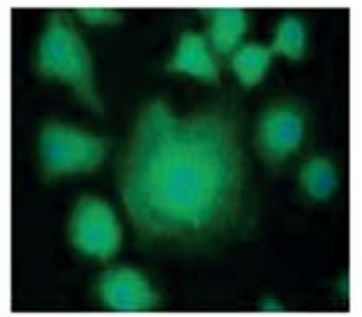

E

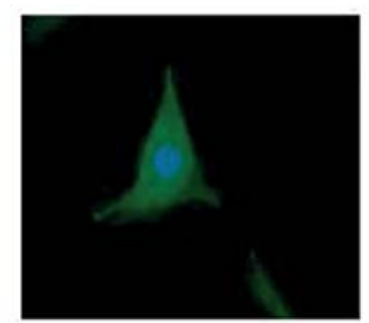

B

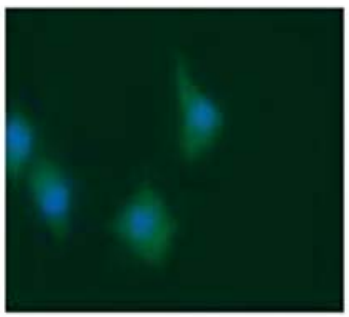

$\mathbf{F}$

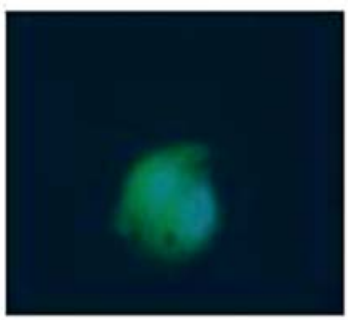

$\mathrm{C}$

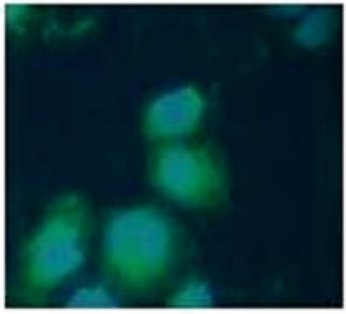

G

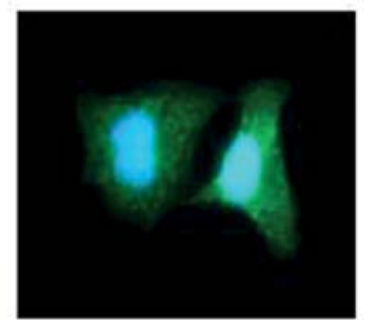

D

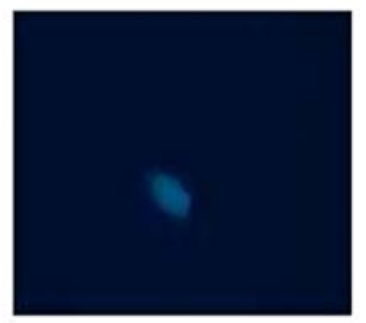

$\mathrm{H}$

Figure 3. HAAH distribution in seven tumor cell lines detected by cell immunofluorescence staning. (A) ACHN; (B) BIU-87; (C) MCF-7; (D) SMMC-7721; (E) Hep-2; (F) HeLa; (G) SKOV; (H) MC3T3; (x100).

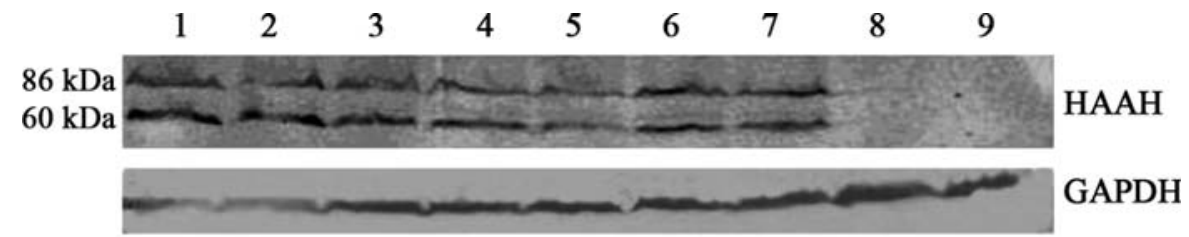

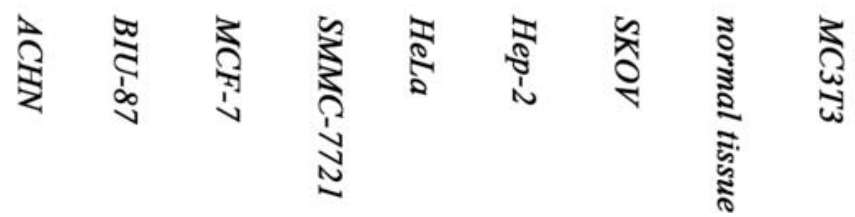

Figure 4. Western immunoblot analysis of HAAH extracted from tumor cell lines and the normal tissue specimens. Total proteins ( 20 mg/ml) from extracts of each tumor cell line and the normal tissue were fractionated. The approximate increases of enzyme protein in the tumor cell lines compared to the normal tissue were: 5.6-fold (ACHN), 6.2-fold (BIU-87), 4.3-fold (MCF-7), 6-fold (SMMC-7721), 4.3-fold (Hep-2), 7.9-fold (HeLa), and 10.1-fold (SKOV).

generated by co-immunizing mice with naked plasmid DNA containing N-terminal domain of encoding HAAH gene and recombinant HAAH polypeptide, which was highly specific and sensitive used as the immunogen (17). Antigen distribution was assessed by determining the binding of HAAH mAb to a variety of tumor cell lines. As shown in Fig. 3, HAAH mAb exhibited high level binding to the four human tumor cell lines (MCF-7, SMMC-7721, HeLa and SKOV). Lower degrees of binding were observed with ACHN, BIU-87 and Hep-2 cell lines. In contrast, normal mouse embryonic osteoblasts MC3T3 were unreactive.

The staining pattern for HAAH in the tumor cells was primarily cytoplasmic with a distinct perinuclear accentuation (Fig. 3) and plasmalemmal, while the normal mouse embryonic osteoblasts exhibited no staining.

Elevated levels of hydroxylase protein in tumor cell lines. When Western blot was carried out using the HAAH mAb, the levels of HAAH in $7(100 \%)$ tumor cells were much greater than in the normal tissue $(\mathrm{P}<0.01)$ (Fig. 4). Equivalent amounts of total protein from the normal tissue or tumor cell lines were prepared for the assay. The molecular weights of the major two species in the tumor cells were respectively $\sim 86 \mathrm{kD}$ and $\sim 60 \mathrm{kD}$, and only very weak bands of the proteins were observed in the normal tissue. The levels of HAAH in the tumor cells were respectively 10.1-fold (SKOV), 7.9-fold (HeLa), 6.2-fold (BIU-87), 6-fold (SMMC-7721), 5.6-fold (ACHN), 4.3-fold (MCF-7) and 4.3-fold (Hep-2) greater than its levels in the normal tissue and mouse embryonic osteoblasts (Fig. 5). Estimates were made by scanning densitometry after normalizing for the internal controls. These results were quite comparable to those previously detected by RT-PCR; thus, the marked increases seen with the tumor cell lines represented true increments over what was observed in the normal tissue.

Immunohistochemistry validation studies. The cellular localization of HAAH in human tumor tissues was confirmed 


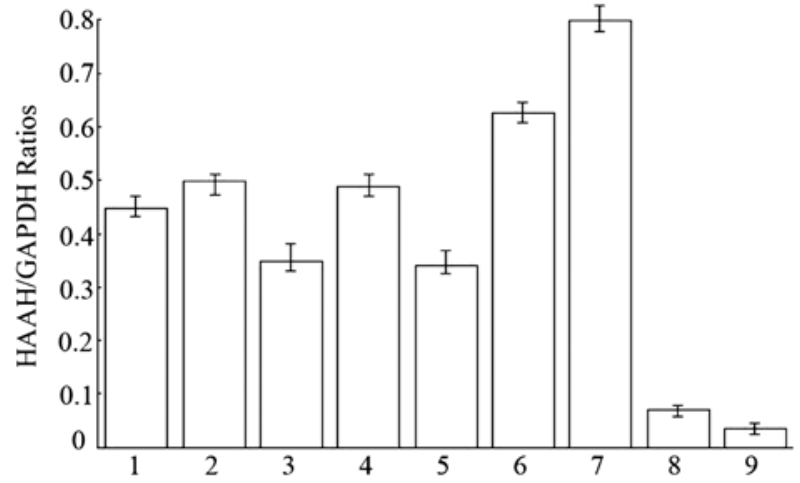

Figure 5. Mean \pm SEM levels of the expressed HAAH in tumors and tumorfree adjacent tissues are depicted graphically. In addition, the mean levels of GAPDH measured in the paired samples are illustrated. 1, ACHN; 2, BIU87; 3, MCF-7; 4, SMMC-7721; 5, Hep-2; 6, HeLa; 7, SKOV; 8, Normal tissue; 9 , MC3T3; (x100).

Table II. Immunohistochemistry results.

\begin{tabular}{lrcccr}
\hline & & \multicolumn{3}{c}{ Expression of HAAH } & \\
\cline { 3 - 5 } & No. & $\begin{array}{c}\text { Negative } \\
(0)\end{array}$ & $\begin{array}{c}\text { Weak } \\
\text { Positive } \\
(1+)\end{array}$ & $\begin{array}{c}\text { Strong } \\
\text { Positive } \\
(2+/ 3+)\end{array}$ & $\begin{array}{r}\text { Positive } \\
\text { ratio } \\
(\%)\end{array}$ \\
\hline Normal tissue & 8 & 8 & 0 & 0 & 0.0 \\
Tumor tissue & 104 & 10 & 2 & 92 & 90.4 \\
\hline
\end{tabular}

by immunohistochemical staining studies (Tables II and III). Immunoreactivity was detected on the cell surface membranes, in the cytoplasm, and in perinuclear zones (Fig. 6). Adjacent benign tissues were negative or weakly focal expressed. Of the 104 tumor samples, 94 (90.4\%) exhibited aspartyl betahydroxylase immunoreactivity using the monoclonal antibody to HAAH.

Fifteen breast carcinomas exhibited high levels $(2+$ or $3+)$ of HAAH immunoreactivity, and only the remaining one had the staining pattern seen in the normal tissue. Distribution of antigen was heterogeneous among the cells in the tumors with high level immunoreactivity. All 16 hepatocellular carcinomas, 11 cholangiocarcinomas and 3 pancreatic cancers examined exhibited intense and uniform immunoreactivity $(2+$ or $3+)$ (Table III; Fig. 6). In the samples of lung carcinomas and colon carcinomas, HAAH immunoreactivity was localized throughout the cytoplasm, but in a distinct and prominent perinuclear pattern (figure not shown). Mucin-producing and well differentiated neoplastic foci within the specimens exhibited the most striking HAAH immunoreactivity. In contrast, nests, cords, and diffusely infiltrative neoplastic cells exhibited low level or absent HAAH immunoreactivity. The high level HAAH expression was a feature of both primary and metastatic lesions. All specimens exhibited immunoreactivity for glyceraldehyde-3-phosphaste dehydrogenase (positive control) and absent immunolabeling with the primary antibody omitted.
Table III. HAAH expressed in different sources of tumor tissues.

\begin{tabular}{lrccc}
\hline Tumor tissue & No. & Negative & Positive & $\begin{array}{c}\text { Positive } \\
\text { ratio }(\%)\end{array}$ \\
\hline Liver cancer & 16 & 0 & 16 & 100 \\
Cholangiocarcinoma & 11 & 0 & 11 & 100 \\
Kidney cancer & 14 & 1 & 13 & 92.8 \\
Breast cancer & 16 & 1 & 15 & 93.7 \\
Cervical cancer & 3 & 0 & 3 & 100 \\
Ovarian cancer & 3 & 1 & 2 & 66.7 \\
Fallopian tube carcinoma & 2 & 0 & 2 & 100 \\
Laryngo carcinoma & 4 & 1 & 3 & 75 \\
Lung cancer & 3 & 1 & 2 & 66.7 \\
Thyroid cancer & 4 & 1 & 3 & 75 \\
Pancreatic & 3 & 0 & 3 & 100 \\
Thymic carcinoma & 1 & 0 & 1 & 100 \\
Prostate cancer & 5 & 1 & 4 & 80 \\
Bladder & 4 & 1 & 3 & 75 \\
Esophagus cancer & 4 & 1 & 3 & 75 \\
Gastric carcinoma & 3 & 1 & 2 & 66.7 \\
Gall bladder & 2 & 0 & 2 & 100 \\
colon cancer & 3 & 0 & 3 & 100 \\
Rectum carcinoma & 1 & 0 & 1 & 100 \\
\hline Total & 104 & 10 & 94 & 88.5 \\
\hline & & & & \\
\hline
\end{tabular}

\section{Discussion}

Aspartyl beta-hydroxylase (AAH) is a member of the $\alpha$-ketoglutarate-dependent dioxygenase family of molecules and catalyzes the hydroxylation of specific aspartyl and asparaginyl residues in epidermal growth factor (EGF)-like domains of certain proteins (5-10). The consensus sequence for AAH hydroxylation is present in proteins such as notch, the notch ligand, jagged, and extracellular matrix molecules such as laminin and tenascin, which have demonstrated roles in cell motility or adhesion $(5,6,8,11)$. The DNA sequence encoding the full-length AAH contains 27 exons and it has a predicted molecular mass of $\sim 86 \mathrm{kD}$. The AAH gene encodes 4 proteins: $\mathrm{AAH}$, humbug, junctate, and junctin, which are generated by alternative splicing of an $\sim 6-\mathrm{kb}$ messenger RNA (mRNA) transcript, with exon sharing and exon swapping mainly within the first 13 exons $(6,20)$. The AAH $(\sim 86 \mathrm{kD})$ and humbug $(\sim 60 \mathrm{kD})$ proteins are the main expressed products of the gene (21). In our study, the two kinds of proteins were detected in all 7 tumor cell lines.

The AAH genes have been documented to be overexpressed in a variety of malignant neoplasms and transformed cell lines, including those of colonic, breast, pancreatic, biliary, or hepatic origin (12-16). In contrast, most normal mature tissues have relatively low levels of AAH expression with the exception in proliferating trophoblastic cells of the placenta and in adrenal glands (12). AAH was initially concerned due to the research report of the Panacea Pharmaceutical Company 


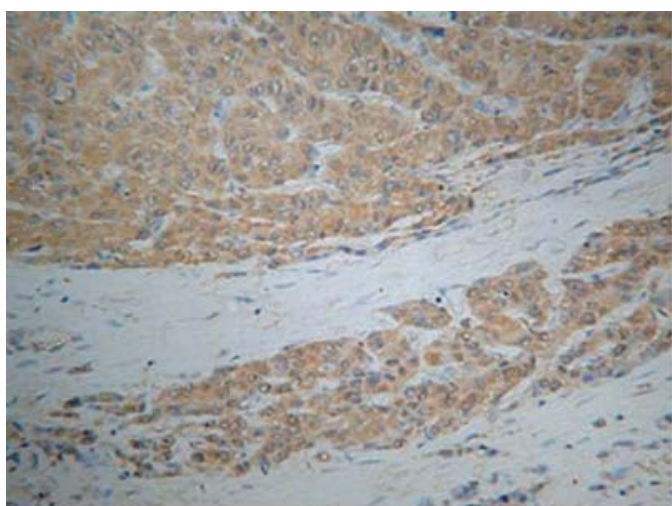

A

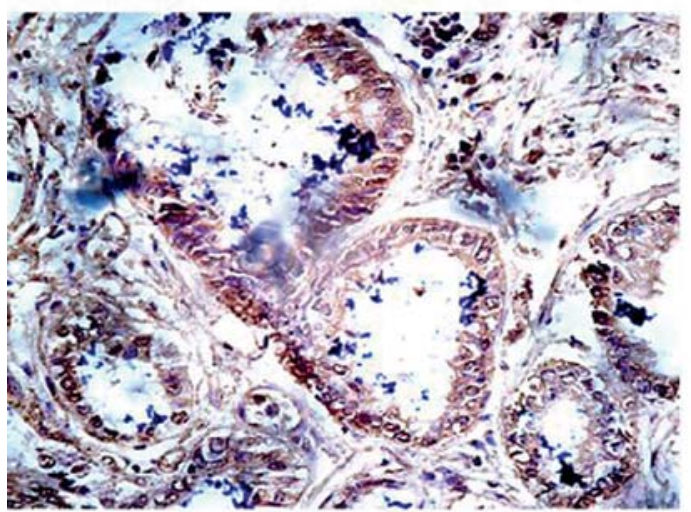

C

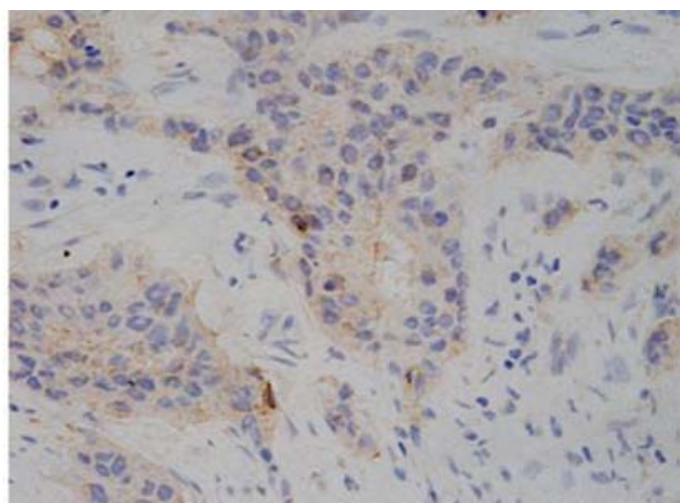

B

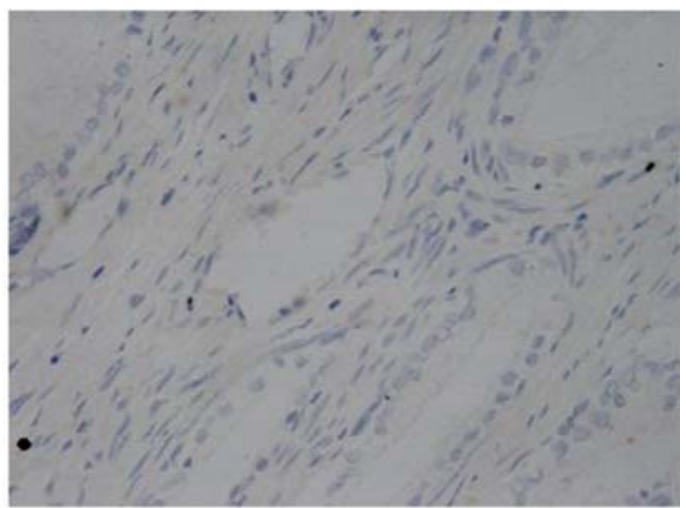

D

Figure 6. Representative examples of immunoreactivity. HAAH immunoreactivity in liver (A), breast (B), pancreatic (C) carcinomas, and in the normal tissue (D). Normal tissue was negative or weakly focal positive; high immunoreactivity was detected in the cytoplasm, and in membranes and perinuclear zones in carcinomas. No immunoreactivity was observed with the primary antibody omitted.

in the United States (22). The company detected 598 cases of 12 kinds of frequent tumors, and AAH was found to be overexpressed in 594 cases (99\%). Lavaissiere et al (12) reported that AAH was expressed at high levels in primary hepatocellular carcinomas, cholangiocarcinomas, breast carcinomas, colon carcinomas and in a variety of transformed cell lines. Studies on AAH expression in Chinese patients with hepatocellular carcinoma (23) showed that AAH was overexpressed frequently in hepatocellular carcinoma, including early-stage small hepatocellular carcinoma, indicating that overexpression of AAH played a role in the development and progression of hepatocellular carcinoma. They suggested that it could possibly be used as a prognostic marker and an immunotarget for anti-tumor agents for hepatocellular carcinoma and other carcinomas (23). Other in vitro assays demonstrated the correlation between increased AAH expression and directional cell motility of neuroblastoma (16) and cholangiocarcinoma (24) cell lines. In addition, overexpressed AAH could be released from the tumorous cells and existed in soluble or free states in human serum and body fluids. The malignant tumors could be screened by titers of AAH in serum (25).

In our previous study, HAAH encoding gene has already been cloned, expressed and purified (17). HAAH-specific monoclonal antibody (MAb) was generated by co-immunizing mice with naked plasmid DNA containing N-terminal domain of encoding HAAH gene and recombinant HAAH polypeptide. The specificity and sensitivity of the obtained MAb was assessed, and it was preliminarily applied to detect the expression of HAAH in seven tumor tissues, including hepatocellular carcinoma, lung cancer, kidney cancer, cholangiocarcinoma, prostate cancer, breast cancer, and glioblastoma by immunohistochemical stain. The results showed that the MAb was highly specific and effective as the immunogen (17). Our present study indicates that HAAH mRNA was overexpressed in all seven (100\%) tumor cell lines examined, although the levels of the gene expression varied from each other. These RT-PCR results correlated well with the findings by Western blotting using the HAAH monoclonal antibody. The molecular weights of the expressed major two species in the tumor cells were respectively $\sim 86 \mathrm{kD}$ and $\sim 60 \mathrm{kD}$. It could be the result of alternative splicing of the mRNA $(26,27)$. The level of HAAH in SKOV cell line was highest, 10.1-fold over than in the normal tissue. Also in other tumor cell lines, the levels of the protein were respectively 7.9-fold (HeLa), 6.2-fold (BIU-87), 6-fold (SMMC-7721), 5.6-fold (ACHN), 4.3-fold (MCF-7) and 4.3-fold (Hep-2) greater than in normal tissue and mouse embryonic osteoblasts. The protein expression levels of HAAH in the tumor cell lines were 
parallel with the mRNA expression level, indicating that the expression is regulated at the transcription level, and mRNA level can represent the protein expression level. Further investigation is required to determine whether the substantially increased expression of HAAH in tumors is merely associative or contributes to the development and/or maintenance of the malignant phenotype.

Antigen distribution was assessed by determining the binding of HAAH mAb to a variety of tumor cell lines. The staining of HAAH was found to mainly exit in the cytoplasm focused around the nucleus and the plasmalemma in the tumor cell lines, while the normal mouse embryonic osteoblasts exhibited no staining. It was suggested that all AAH-related proteins share common N-terminal exons (exons 2 and 3 ) that encode the transmembrane domain and a portion of the cytoplasmic domain $(5,6,20)$. The distribution of HAAH in the tumor cell lines may be associated with the sequences of its $\mathrm{N}$-terminus. The immunohistochemical staining studies demonstrated that HAAH was overexpressed in a significant proportion $(90.4 \%)$ of 104 different sources of tumor tissue samples, while adjacent benign tissues were negative or weakly focal expressed. Among the 19 kinds of tumor specimens detected, 9 kinds showed $100 \%$ positive rates of immunoreactivity to HAAH MAb, and other 3 kinds presented the lowest positive rate of $66.7 \%$ (Table III). The results suggest highly correlation between the overexpression of HAAH and many human malignancies. However, the present studies were not sufficient to be concluded that HAAH was detected to be overexpressed at high positive rates in some tumor tissues or at low positive rates in others due to the limited quantities of tumor tissue samples detected. Further investigation is required to include many more tumor specimens and their stage, location, patient age, gender, and vital statistics.

In conclusion, HAAH gene is frequently overexpressed in varieties of carcinomas of Chinese patients, indicating that overexpression of the enzyme plays a role in the development and progression of these carcinomas. It could possibly be used as a prognostic marker and an immunotarget for anti-tumor agents for these carcinomas. This would be especially beneficial for patients with early stage of cancer for which the addition of adjuvant chemotherapy is debatable. Further investigation is required to define the roles of HAAH in the development and/or maintenance of tumors and the exact molecular pathways leading to carcinogenesis.

\section{Acknowledgements}

This study was supported by Science and Technology Innovation Fund of Northwestern Ploytechnical University (No. KC04) and Basic Research Fund of Northwestern Polytechnical University (No. JC200921).

\section{References}

1. Taouli B, Losada M, Holland A and Krinsky G: Magnetic resonance imaging of hepatocellular carcinoma. Gastroenterology 127: 144-152, 2004.

2. Baron RL and Brancatelli G: Computed tomographic imaging of hepatocellular carcinoma. Gastroenterology 127: 133-143, 2004.

3. Suriawinata A and Xu R: An update on the molecular genetics of hepatocellular carcinoma. Semin Liver Dis 24: 77-88, 2004
4. Feitelson MA, Pan J and Lian Z: Early molecular and genetic determinants of primary liver malignancy. Surg Clin North Am 84: 339-354, 2004.

5. Dinchuk JE, Focht RJ, Kelley JA, Henderson NL, Zolotarjova NI, Wynn R, Neff NT Link J, Huber RM, Burn TC, Rupar MJ, Cunningham MR, Selling BH, Ma J, Stern AA, Hollis GF, Stein RB and Friedman PA: Absence of post-translational aspartyl betahydroxylation of epidermal growth factor domains in mice leads to developmental defects and an increased incidence of intestinal neoplasia. J Biol Chem 277: 12970-12977, 2002.

6. Dinchuk JE, Henderson NL, Burn TC, Huber R, Ho SP, Link J, O'Neil KT, Focht RJ, Scully MS, Hollis JM, Hollis GF and Friedman PA: Aspartyl beta-hydroxylase (Asph) and an evolutionarily conserved isoform of Asph missing the catalytic domain share exons with junctin. J Biol Chem 275: 39543-39554, 2000.

7. Gronke RS, Welsch DJ, Van Dusen WJ, Garsky VM, Sardana MK, Stern AM and Friedman PA: Partial purification and characterization of bovine liver aspartyl beta-hydroxylase. J Biol Chem 265: 8558-8565, 1990.

8. Ho SP, Scully MS, Krauthauser CM, Wexler EJ, Stow MD, Dinchuk JE, Kerr JS and Friedman PA: Antisense oligonucleotides selectively regulate aspartyl beta-hydroxylase and its truncated protein isoform in vitro but distribute poorly into A549 tumors in vivo. J Pharmacol Exp Ther 302: 795-803, 2002.

9. Korioth F, Gieffers $\mathrm{C}$ and Frey J: Cloning and characterization of the human gene encoding aspartyl beta-hydroxylase. Gene 150: 395-399, 1994.

10. McGinnis K, Ku GM, Van Dusen WJ, Fu J, Garsky V, Stern AM and Friedman PA: Site-directed mutagenesis of residues in a conserved region of bovine aspartyl (asparaginyl) betahydroxylase: evidence that histidine 675 has a role in binding $\mathrm{Fe}^{2+}$. Biochemistry 35: 3957-3962, 1996.

11. Ince N, de la Monte SM and Wands JR: Overexpression of human aspartyl (asparaginyl) beta-hydroxylase is associated with malignant transformation. Cancer Res 60: 1261-1266, 2000.

12. Lavaissiere L, Jia S, Nishiyama M, de la Monte S, Stern AM, Wands JR and Friedman PA: Overexpression of human aspartyl (asparaginyl) beta-hydroxylase in hepatocellular carcinoma and cholangiocarcinoma. J Clin Invest 98: 1313-1323, 1996.

13. de la Monte S, Tamaki S, Cantarini MC, Ince N, Wiedmann M, Carter JJ, Lahousse SA, Califano S, Maeda T, Ueno T, D'Errico A, Trevisani $\mathrm{F}$ and Wands JR: Insulin receptor substrate-1 regulates aspartyl-asparaginyl-beta hydroxylase and hepatocellular carcinoma invasiveness. J Hepatol 44: 971-983, 2006.

14. Maeda T, Taguchi K, Aishima S, Shimada M, Hintz D, Larusso N, Gores G, Tsuneyoshi M, Sugimachi K, Wands JR and de la Monte SM: Clinicopathological correlates of aspartyl (asparaginyl) betahydroxylase over-expression in cholangiocarcinoma. Cancer Detect Prev 28: 313-318, 2004.

15. Palumbo KS, Wands JR, Safran H, King T, Carlson RI and de la Monte SM: Human aspartyl (asparaginyl) beta-hydroxylase monoclonal antibodies: potential biomarkers for pancreatic carcinoma. Pancreas 25: 39-44, 2002.

16. Sepe PS, Lahousse SA, Gemelli B, Chang H, Maeda T, Wands JR and de la Monte SM: Role of the aspartyl-asparaginyl-betahydroxylase gene in neuroblastoma cell motility. Lab Invest 82: 881-891, 2002.

17. Xue T, Xue XP, Huang QS, Wei L, Sun K and Xue T: Monoclonal antibodies against human Aspartyl (Asparaginyl) betahydroxylase developed by DNA immunization. Hybridoma 28: 251-257, 2009.

18. Yang H, Chen JX, Yang GP, Zhang XH, Liu R and Xue XP: Protection of Japanese flounder (Paralichthys olivaceus) against Vibrio anguillarum with a DNA vaccine containing the mutated zinc-metalloprotease gene. Vaccine 27: 2150-2155, 2009.

19. Laemmli UK: Cleavage of structural proteins during the assembly of the head of bacteriophage T4. Nature 277: 680-685, 1970.

20. Treves S, Feriotto G, Moccagatta L, Gambari R and Zorzato F: Molecular cloning, expression, functional characterization, chromosomal localization, and gene structure of junctate, a novel integral calcium binding protein of sarco(endo)plasmic reticulum membrane. J Biol Chem 275: 39555-39568, 2000.

21. Rockville, MD, PRNewswire/Panacea Pharmaceuticals, Inc. Oct. 23, 2002. (http://www.panaceapharma.com/press/ $10 \_23$ 2002.htm).

22. Rockville, MD, BW HealthWire/Panacea Pharmaceuticals, Inc. April 19, 2002. (http://www.panaceapharma.com/press/ 10_23_2002.htm). 
23. Xian ZH, Zhang SH, Cong WM, Yan HX, Wang K and Wu MC: Expression of aspartyl beta-hydroxylase and its clinicopathological significance in hepatocellular carcinoma. Modern Pathol 19: 280-286, 2006.

24. Maeda T, Sepe P, Lahousse S, Tamaki S, Enjoji M, Wands JR and de la Monte SM: Antisense oligodeoxy-nucleotides directed against aspartyl (asparaginyl) beta-hydroxylase suppress migration of cholangiocarcinoma cells. J Hepatol 38: 615-622, 2003

25. Hossein AG: Cancer diagnostics integrated with therapeutics: a comprehensive approach to managing the disease. J Biomed Biotechnol 4: 175-176, 2004.
26. Jia S, McGinnis K, Van Dusen WJ, Burke CJ, Kuo A, Griffin PR, Sardana MK, Elliston KO, Stern AM and Friedman PA: A fully active catalytic domain of bovine aspartyl (asparaginyl) betahydroxylase expressed in Escherichia coli: characterization and evidence for the identification of an active-site region in vertebrate alpha-ketoglutarate-dependent dioxygenases. Proc Natl Acad Sci USA 91: 7227-7231, 1994.

27. Jia S, Van Dusen WJ, Diehl RE, Kohl NE, Dixon RA, Elliston KO, Stern AM and Friedman PA: cDNA cloning and expression of bovine aspartyl (asparaginyl) beta-hydroxylase. J Biol Chem 267: 14322-14327, 1992. 